\title{
A Study of the Ethical Dilemmas Experienced by School Psychologists in Portugal
}

\author{
Sofia A. Mendes, Inês M. G. Nascimento, and Isabel M. P. Abreu-Lima \\ Faculty of Psychology and Educational Sciences \\ University of Porto \\ Leandro S. Almeida \\ Department of Educational Psychology and Special Education \\ University of Minho
}

\begin{abstract}
This study examines the ethical dilemmas and difficulties encountered by Portuguese school psychologists. As part of a larger survey, participants were asked about ethical issues faced in daily practice and asked to describe ethical incidents. Of the 477 respondents, 274 reported 441 ethically troubling or challenging situations. Responses were coded into a six-category system based on the code of ethics of Portuguese psychologists. Most of the reported dilemmas concerned privacy and confidentiality principles $(53 \%)$. Results are discussed in light of relevant literature and international findings. Implications for the development of the profession and future research are provided.
\end{abstract}

Keywords: ethical dilemmas, school psychologists, survey

Since 2008, the access to and professional practice of psychology in Portugal is regulated by the Order of Portuguese Psychologists (OPP) (Decree-law no. 57/2008). OPP membership is mandatory, and nearly 20,000 psychologists are represented by this organization. Within its scope of competence, the OPP has recently approved the Code of Ethics of the Portuguese Psychologists (OPP, 2011) and instituted a judicial ethics board to handle complaints against their members. The OPP (2011) code is in line with the European Federation of Psychologists' Associations (EFPA) Meta-code of Ethics (EFPA, 2005), and is mostly in accordance with the code of ethics of the American Psychological Association (APA) (APA 2010). Its principles also reflect the moral and ethical values of the Universal Declaration of Ethical Principles for Psychologists (Gauthier, Pettifor, \& Ferrero, 2010).

The OPP (2011) code of ethics is organized around five general principles and eight enforceable rules of conduct or ethical standards. The general principles are grounded in the ideals of psychological intervention: (a) respect for the person's rights and dignity, (b) competence, (c) responsibility, (d) integrity, and (e) beneficence and no maleficence. The ethical standards are conceptualized as minimum standards of acceptable conduct with which association members

Correspondence should be addressed to Sofia A. Mendes, Rua Alfredo Allen, Sala FPCE136, 4200-135, Porto, Portugal. E-mail: sofia.a.mendes@gmail.com 
are expected to comply: (a) informed consent, (b) privacy and confidentiality, (c) professional relationships, (d) psychological assessment, (e) psychological practice and intervention, (f) training and supervision, $(\mathrm{g})$ research, and $(\mathrm{h})$ public statements. These principles are then detailed throughout 82 standards (OPP, 2011).

Members of the OPP work in diverse areas of professional psychology. Presently, no psychology specialization has official recognition, and only the title "psychologist" is regulated by law (Mendes, Abreu-Lima, Almeida, \& Simeonsson, 2014). Therefore, the OPP (2011) code of ethics is broad in nature and intends to guide practitioners in all areas and settings of psychological practice. Nevertheless, in the short term, the OPP foresees the creation of specialty areas in psychology and the establishment of more specific guidelines for professional conduct. In 2012, it was estimated that about $22 \%$ of OPP members worked in the fields of school and education psychology, the second most represented area of professional practice, following clinical psychology (OPP, 2012). According to the Ministry of Education, in the school year 2014/2015, 778 psychologists were providing school-based psychological services in public schools. This number represents an increase of $9 \%$ compared to the previous year. The number of practitioners performing the same functions in private schools is unknown.

In Portugal, school psychology services are regulated by the Ministry of Education's statutes and regulations. Nevertheless, there are not many laws governing the profession. The most relevant law is the decree-law no. 190/1991 of May 17, 1991, which created the psychology and guidance services and defined its competencies, organization, and operation mode (see Mendes et al., 2014, for further details). Subsequent laws have reinforced school psychologists' roles and responsibilities regarding vocational education (e.g., Ordinance no. 292-A/2012), special education (e.g., Decree-law no. 3/2008), repeated school retention (e.g., Normative order no. 13/2014), and school violence (Decree-law no. 51/2012), albeit neither of these statutes enforces procedures or standards for psychological practice and the delivery of school psychology services is left to the discretion of practitioners and/or school boards.

When compared to other psychology specialties, the professional practice of school psychology has singular characteristics. The profession can primarily be conceptualized as an indirect rather than a direct service specialty (Gutkin \& Conoley, 1990). School psychologists often work with teams, systems, and groups, delivering services to a wide range of clients (i.e., students, families, schools, and the community). As a result of working in the intersection of several systems and performing multiple roles (i.e., assessors, consultants, and counselors), professionals frequently deal with conflicting interests, values, and beliefs (Fisher, 2009; Jacob, Decker, \& Hartshorne, 2011; Knauss, 2001; Koocher, 2008; Lasser \& Klose, 2007; McNamara, 2011). By virtue of the uniqueness of their work context and primary clients (i.e., students), school psychologists may encounter ethical dilemmas that typically do not arise in other settings and when working with adult clients. As such, practitioners must regularly address complex issues related to privacy, confidentiality, informed consent, and multiple relationships (Jacob et al., 2011; Koocher, 2008; Lasser \& Klose, 2007; Rae, Sullivan, Razo, \& Alba, 2009).

The practice of school psychology is also influenced by law, ethical standards, and institutional contexts (Jacob et al., 2011; McNamara, 2011; Williams \& Armistead, 2011). Ethical and legal standards are critical for guaranteeing the quality of the services provided, as well as to protect the rights of students, families, and schools (National Association of School Psychologists [NASP], 2006). On the other hand, schools typically possess a unique culture and expectations regarding the school psychologists' professional conduct and roles (Fagan \& Wise, 2007). Therefore, 
a competent school psychologist must be knowledgeable, sensitive, and capable of reconciling the complex range of clients' requirements with their legal and ethical duties (Flanagan \& Miller, 2010). Codes of ethics are key tools to support practitioners in achieving this latter goal by informing professionals and the general public about the expectations regarding the responsibilities of a profession (Sinclair, Poizner, Gilmour-Barrett, \& Randall, 1987). In turn, a strong foundation in professional ethics would increase the practitioner's ability to anticipate and possibly prevent ethical problems from occurring and to make sound choices when ethical challenges arise (Jacob et al., 2011).

Overall, the education and training of psychologists in Portuguese universities is not systematically documented, and no study has accurately examined the nature of ethics training in psychology programs. Therefore, it is unknown to what extent, over the years, psychology programs have been committed to ethics education.

The inclusion of Portugal in the European Union has had significant implications for the development of psychology, namely, in terms of the academic and professional preparation (Menezes, Teixeira, \& Fidalgo, 2007). Particularly the reorganization of European higher education system, due to the Bologna Declaration, and EFPA's proposal of the European Certificate in Psychology have helped establishing minimum expectations and standards for psychology graduate and undergraduate programs (for further details, see European Commission, 2013; EFPA, 2013).

Currently, and in line with the Bologna Declaration requirements, the training of psychologists lasts 5 years and is organized in a 3-year (bachelor) plus 2-year (master) curriculum. The master's degree is considered the basic qualification for entering the profession; it allows students to specialize in an area of psychology but must be followed by a supervised professional internship accredited by the OPP. In what concerns ethics training, most psychology programs offer a formal ethics course only at the bachelor's level, commonly mandatory and lasting one semester. Ethical issues can be explicitly addressed in different subjects of the curriculum, though this is highly left to the discretion of each teacher.

To promote the ethical competences of new members, during professional internship, trainee psychologists must attend a 90-hr training course held by the OPP in a blended learning format, which comprises a 24-hr module on ethics. The ethics training module aims to help the beginner psychologist to understand the practical or instrumental importance of the professional code of ethics and to apply the ethical principles it establishes in context-specific situations. For licensed practitioners, the OPP provides distance learning and continuing education opportunities in a variety of topics, including ethics, but it does not impose continuing education requirements on its members. The OPP (2011) also states that professional ethics should be lectured at all levels of education and in professional development activities. Because these measures are quite recent, it is not feasible to assert their impact on the profession as a whole.

To demonstrate their commitment to ethics, and to promote high standards of ethical conduct among its members, some professional associations have developed codes of ethics and conduct to support those working in school settings (e.g., International School Psychology Association, 2011; NASP, 2010). In parallel, several studies have explored ethical issues in professional psychology with implications for school psychology (Dailor \& Jacob, 2011; JacobTimm, 1999; Pettifor \& Sawchuk, 2006; Pope \& Vetter, 1992). Most of these studies relied on United States samples and used the critical incident technique or structured inquiries. These studies are reviewed in the following paragraphs. 
Pope and Vetter (1992) are responsible for one of the most emblematic studies on psychologists' professional ethics. Using the critical incident technique, the authors surveyed 670 general APA members on the ethical dilemmas they had encountered. A total of 703 incidents were obtained and classified into one of 23 categories of analysis. Only $2 \%$ of the incidents described fell into the school psychology category and reflected practitioners' struggles to act in the child's best interest despite pressure from administrators. The three most frequently reported dilemmas pertained to (a) confidentiality (18\%); (b) blurred, dual, or conflictual relationships (17\%); and (c) payments $(14 \%)$.

Pope and Vetter's (1992) design was later replicated in eight countries (i.e., United Kingdom, Norway, Finland, Canada, Sweden, New Zealand, South Africa, and Mexico), seeking to highlight the differences and similarities in the types and frequency of ethical dilemmas faced by general psychologists. Combining the data obtained in these studies and those previously reported by Pope and Vetter $(n=2,698)$, Pettifor and Sawchuk (2006) found the following top three reported ethical dilemmas: confidentiality (25\%), dual relationships (13\%), and competence $(8 \%)$. The percentage of dilemmas within the school psychology category was low for all countries surveyed, with the highest percentage reported in the United Kingdom (7\% in a total of 122 dilemmas). Lindsay and Coloney (1995), the authors of the latter study, described that the majority of the dilemmas in this category concerned the challenge to reconcile needs with service provision. The absence of information hampers our understanding of the nature of the dilemmas experienced by school psychologists in the other participant countries.

Using a modified version of the Pope and Vetter (1992) survey, Jacob-Timm (1999) explored the ethical dilemmas faced by a sample of 226 NASP members. A total of 222 incidents were described and organized into 19 categories. The most frequent dilemmas identified referred to administrative pressure to behave unethically (22\%), assessment and diagnostic procedures $(14 \%)$, confidentiality (14\%), and unsound educational practices $(13 \%)$. The results of this study were subsequently used by Dailor and Jacob (2011) to develop a structured questionnaire for further investigation.

A decade later, surveying a representative sample of NASP members $(n=208)$, Dailor and Jacob (2011) found that, in the previous year, $86 \%$ had witnessed ethical transgressions related with assessment, $79 \%$ with intervention practices, and $76 \%$ with administrative pressure. The most troublesome dilemmas experienced included whether to report suspected child abuse (28\%), whether to disclose students' risky behaviors to parents (25\%), handling colleagues' unethical conduct (25\%), and balancing parents' rights to access test protocols while maintaining test security (23\%). Dailor and Jacob also asked participants to report their top three areas of ethical concerns, which were ordered as follows: administrative pressure to act unethically, unsound educational practices, and assessment-related issues.

Other researchers have also acknowledged administrative pressures to practice unethically as a major issue faced by school psychologists, focusing their studies on practitioners' responses to such pressure (e.g., Helton \& Ray, 2006, 2009; Helton, Ray, \& Biderman, 2000). These authors have linked these kinds of dilemmas to two central topics in the profession: first, the dual role of school employee and pupil advocate, and second, the conflicts of loyalties that emerged from having to honor the law, professional, and ethical standards while being committed with the employer's perceived needs, expectations, and directives.

A literature review showed that a single published study has explored the ethical dilemmas encountered by school psychologists in Portugal. This study, authored by Carita (2012), examined 
177 school psychologists in order to identify and analyze ethically troubling situations. Beyond the already limited sample of practitioners, the author obtained responses from only 41 school psychologists, who described 43 incidents. A system of 11 categories was created based on a code of ethics that predated the OPP's. This code was produced by the Portuguese Psychologists' Union, a professional association of voluntary affiliation. Carita's study cited confidentiality $(41 \%)$, relationships with third parties $(24 \%)$, and self-determination of clients (12\%) as the three most common sources of dilemmas for Portuguese practitioners. According to Carita, most dilemmas related to confidentiality expressing practitioners' concerns with defending the dignity of students, the consequences of breaking confidentiality, the harm to the psychologists-student relationship, and the efficacy of the interventions. The author also pointed out that most of these dilemmas occurred in the context of relationships with third parties, relevant to the interventions.

If professional ethics in areas such as psychotherapy, clinical, and counseling psychology are theoretically and empirically well represented in the literature, the same cannot be said for school psychology (Clemente, Espinosa, \& Urra, 2011; Tryon, 2000, 2001). Despite the profession's foundation in empiricism, professional school psychology still lacks empirical data regarding ethical issues. Most existing studies originated in the United States and reflected North American culture and values. At the national level, the paucity and limitations of the academic literature and research available on this topic reveals that ethics in school psychology is a priority area for investigation.

Therefore, the goals of this study were to explore the ethical dilemmas experienced by Portuguese school psychologists and compare findings on an international basis. This information can be used to advance practices and policies relevant to the profession in Portugal by (a) empirically informing the development of specific guidelines or future revisions of the code of ethics and (b) informing initial and ongoing ethics training programs (Dailor \& Jacob, 2011; Jacob-Timm, 1999; Lindsay \& Coloney, 1995; Pettifor \& Sawchuk, 2006; Pope \& Vetter, 1992; Slack \& Wassenaar, 1999). This is also of practical value at a time when psychology in Portugal is taking important steps toward professionalization, namely, by legally recognizing specialties in psychology.

\section{METHOD}

\section{Participants}

Of the 477 school psychologists who completed the survey, $88 \%$ were women. On average, participants were 39 years old $(S D=8.30)$, had 12 years of professional experience as a school psychologist $(S D=7.40)$, and worked 8 years in their current school $(S D=6.43)$. Sixty-three percent of the respondents reported holding a licentiate degree, $35 \%$ a master's degree, and $2 \%$ a doctoral degree. Most participants reported working in public schools (82\%). Of those, $45 \%$ served in elementary schools, $25 \%$ in secondary schools, and $31 \%$ in schools that combined both education levels. An estimated 59\% response rate was obtained from practitioners working in the public education sector. This number was computed considering the best estimate available at the time of the survey for the total number of school psychologists working in this sector $(n=650)$. Regarding professionals working in the private education sector, such an estimate is not possible because the percentage of this population is not known. According to OPP's (2014) official data, 
$89 \%$ of school psychologists are female and are 39 years old on average, and around $60 \%$ hold a licentiate degree. Therefore, one can assume that the sample under study reasonably represents the demographic characteristics of the population from which it was drawn.

\section{Instrument}

The request to describe ethical dilemmas was part of a larger nationwide survey aimed to examine the state of school psychology as a profession in Portugal (see Mendes et al., 2014, for further details). Data regarding ethical dilemmas were collected through a single question, inquiring if, in the current school year, practitioners had encountered ethically troubling or challenging situations. Those who responded affirmatively to this question were asked to describe up to three incidents. Additional information concerning practitioners' personal and professional background and school setting characteristics were also collected.

\section{Procedures}

The survey was administered online at the end of the school year 2011-2012. Due to the absence of an up-to-date and publicly available list of school psychologists and organizational differences between the public and private education sectors, two different sampling methods were used. In public schools, the survey was disseminated with the permission and support of the Ministry of Education throughout the school network, via regional structures. In the case of private schools, the authors identified a list of educational establishments using national databases and contacted them without prior knowledge if they had school psychology services. In both cases, the survey was primarily disseminated via e-mail, addressed to the schools' board. In this e-mail, the recipient was asked to forward it to school psychologists. Subjects' right to privacy and voluntary participation were safeguarded. For more details on the survey development and implementation, see Mendes et al. (2014).

\section{Data Analysis}

The reported dilemmas were analyzed using the qualitative research method of content analysis. The OPP (2011) code of ethics was used as a framework of reference to establish a categorization system. Using an iterative process, a number of preliminary categories were defined and then reduced through repeated analysis to eliminate overlap and ensure coding consistency. Each dilemma was assigned to a single category based on the main ethical issue raised. The categories were quantitatively analyzed, and frequencies were obtained. To ensure reliability of the categorization, two researchers analyzed the data independently. The software NVivo version 10 and IBM SPSS version 22.0 were used to perform quantitative and qualitative data analysis.

\section{RESULTS}

Of the 477 participants who returned the survey, 274 (57\%) reported 441 ethically troubling or challenging situations, which were classified into six categories (Table 1). Those who did 
TABLE 1

Categories of Ethical Dilemmas

\begin{tabular}{|c|c|c|c|}
\hline Category & Description & $F$ & $\%$ \\
\hline $\begin{array}{l}\text { Privacy and } \\
\text { confidentiality }\end{array}$ & $\begin{array}{l}\text { Concerns about the ethical and legal limitations of confidentiality } \\
\text { and sharing sensitive and confidential information. }\end{array}$ & 235 & 53 \\
\hline $\begin{array}{l}\text { Psychological practice } \\
\text { and intervention }\end{array}$ & $\begin{array}{l}\text { Concerns about the scientifically informed and the rigorous and } \\
\text { responsible exercise of psychology, as well as the respect for } \\
\text { individual differences. }\end{array}$ & 68 & 15 \\
\hline $\begin{array}{l}\text { Relationships with other } \\
\text { professionals }\end{array}$ & $\begin{array}{l}\text { Issues arising from relationships with other professionals, including } \\
\text { psychologists. }\end{array}$ & 42 & 10 \\
\hline Psychological assessment & Concerns related to psychological diagnosis and assessment. & 38 & 9 \\
\hline $\begin{array}{l}\text { Informed consent and } \\
\text { self-determination }\end{array}$ & $\begin{array}{l}\text { Issues related to parental consent, parent involvement, and clients' } \\
\text { rights of autonomy and self-determination. }\end{array}$ & 31 & 7 \\
\hline Reports and records & $\begin{array}{l}\text { Concerns about the production, storage, access or dissemination of } \\
\text { reports and other documents. }\end{array}$ & 27 & 6 \\
\hline
\end{tabular}

Note. $n=441$.

not report ethical dilemmas did not significantly differ from those who did regarding age, $t(475)=0.42, p=.68$; years of experience as a school psychologist, $t(475)=0.84, p=.40$; or in the current school setting, $t(475)=0.18, p=.87$. The chi-squared test showed a significant association between reporting ethical dilemmas and the highest academic degree held, $\chi^{2}(1,454)=4.33, p=.03$. Respondents with master's or doctoral degrees were more likely to report ethical issues (64\%) when compared to those holding a licentiate degree $(53 \%)$. However, no association was found between reporting ethical dilemmas and practitioners' area of specialization prior to entering the profession, $\chi^{2}(1,477)=1.34, p=.51$. The characteristics of the professional setting of those who reported no ethical dilemmas did not significantly differ from those who did when considering the type of educational establishment (i.e., public vs. private), $\chi^{2}(1,477)=0.34, p=.56$; the school's geographical setting (i.e., rural vs. suburban vs. urban), $\chi^{2}(2,455)=2.77, p=.25$; student populations served (i.e., elementary vs. secondary vs. multiple grade groups), $\chi^{2}(2,477)=0.79, p=.67$; and school psychologist-to-student ratio, $t(475)=0.05, p=.96$. Table 1 provides a summary of the categorization system and the frequency of respondents within each category. Because the main interest of this study was the content of ethical dilemmas, the variants of dilemmas included in each category are described.

\section{Privacy and Confidentiality}

As Table 1 shows, the most frequently reported dilemmas involved managing private and confidential information. School psychologists experienced different difficulties in this area, which are detailed in descending order of frequency.

Of the 235 (53\%) dilemmas in this category, 99 involved doubts and concerns about sharing confidential information with school personnel, parents, and professionals from agencies outside the school setting (e.g., health and social welfare authorities). The most frequent difficulty identified was to determine when and which information might or should be disclosed to 
any of these parties, be it in the context of regular contact, teamwork, teachers' meetings, or by request.

Difficulties in dealing with the legal obligation to report suspected child abuse were reported by 41 participants. Some practitioners mentioned that when faced with child neglect or suspected physical, sexual, or emotional maltreatment, they struggled with the decision of whether to contact child protective services and were unsure about the best procedures to follow in this matter. Concerns that breaching confidentiality and reporting abuse would disrupt the therapeutic relationship and worries about its effects on children and families were also mentioned. Similar dilemmas were described by 35 school psychologists regarding the decision of breaking confidentiality about risky adolescent behaviors (e.g., risky sexual behavior, drug abuse or trafficking, antisocial activities, and suicidal behavior) and teenage pregnancy.

The pressure from teachers and administrators regarding the disclosure of private and confidential information was reported by 25 participants. Nineteen participants broadly described difficulties in recognizing and deciding when professional secrecy should or should not be violated. Twelve additional dilemmas involved the legal obligation to release client information while respecting client's privacy and confidentiality rights. In this case, the practitioners' main difficulty was the selection of the information to be provided in legally required reports and testimonies. The remaining four incidents referred to violations of confidentiality and privacy of psychological records by school personnel.

\section{Psychological Practice and Intervention}

The second most frequent category in the survey was psychological practice and intervention, with $68(15 \%)$ dilemmas. Following the structure of the OPP (2011) code of ethics, and the rules of conduct that comprise this ethical standard, the dilemmas within this category were organized into four groups, which are described next.

Conflicts of interest. Mentions of potential or actual conflicts of interest were identified in 31 responses. Twelve participants reported being pressed to refer or induce students to choose a course provided by the educational establishment where they were working, favoring the school's interests at the expense of the students' interests. Seven respondents cited having knowledge of organizational and administrative decisions that primarily took into consideration schools' or teachers' interests and that could jeopardize students. Seven additional responses described the challenging need to deal with parental divorce and child custody cases, namely, when one of the parents requested the school psychologist's professional opinion for child custody evaluation purposes. Two professionals, who also engaged in private practice, referred to providing private services to students of the schools to which they were currently assigned, questioning if this was ethically acceptable. The question "Who is the client?" was found in the responses of three participants, questioning who the primary recipient of school psychology services was (i.e., students, parents, schools), specifically when conflicting interests of multiple parties were involved.

Multiple relationships. Thirteen responses focused on multiple relationships that may diminish the school psychologist's professional effectiveness. Of these, seven referred to being asked by the school personnel to provide psychological services to family members or counseling on their own personal problems. The remaining five were about the simultaneous provision of 
psychological services to different family members (e.g., brothers and sisters, cousins), arguing that the lack of community or family resources precluded making appropriate referrals.

Competence boundaries and job performance. Twelve responses addressed competence boundaries and job performance concerns. Six of these were about the need or request to practice outside the school psychologist's area of expertise, professional experience, or role boundaries. Two additional responses expressed concerns about the quality of services provided to foreign students and one to homosexual students. Although the first two revealed apprehension about not being qualified and competent for the task, the third assumed that their prejudice against homosexuality might interfere with professional effectiveness. One participant described the pressure resulting from caseloads and multiple activities, to a point where quality work could not be assured as ethically challenging.

Facilities and fees. Twelve responses pointed out issues related to inappropriate workspaces, with participants reporting that the facilities in which they developed their professional practice did not guarantee privacy or lacked appropriate equipment. Last but not least, one respondent raised concerns regarding receiving gifts from clients.

\section{Relationships With Other Professionals}

Forty-two responses (10\%) reported dilemmas or ethically challenging situations stemming from the relationship with other professionals and colleagues. Seventeen references were made to unsound educational practices by teachers and the difficulties experienced when trying to confront them about the need to change their beliefs and behavior. These responses included concerns about (a) inappropriate teaching and discipline practices, (b) failure to accommodate the diverse learning needs of students or to address the needs of special education populations, and/or (c) cases where teachers overlooked school psychologists' recommendations regarding students. Thirteen responses cited duplication of interventions, that is, situations where a psychologist established a professional relationship with a client being assisted by another colleague for the same purpose.

Five additional participants described being pressured by teachers and administrators to reevaluate students or to replace an ongoing intervention process conducted by other psychologists, external to the school setting. These requests were usually associated with reports of distrust about the quality of the services provided by non-school-based practitioners, or in disagreement with professionals' opinion or diagnosis. Four participants reported being aware of psychological practice by unqualified individuals and six others referred unethical behavior by some colleagues. Finally, three respondents mentioned as ethically challenging to be confronted and to deal with other professionals that performed poorly.

\section{Psychological Assessment}

Thirty-eight (9\%) responses addressed ethical issues related to psychological assessment and diagnosis. The use of outdated tests or instruments, unlicensed copies of copyright-protected assessment materials, and measures with psychometric qualities not suitable for the Portuguese population were reported by 16 participants. Seven ethically problematic situations focused on 
doubts or disagreements about the diagnosis made by other professionals and one on assessment errors made by other psychologists. Seven additional responses reflected concerns about assessment and eligibility for special education services. Examples included (a) performing a reevaluation of students that might result in disqualification for special education; (b) knowing students that were inappropriately placed in special education; and (c) managing disagreements between teachers, parents, and/or the school psychologist about whether a child was qualified for special education services.

Four responses described concerns related to a request for a professional's opinion about the repeated retention of students, as required by law. In these cases, practitioners revealed their fear of lacking sufficient time to perform an adequate psycho-pedagogical evaluation to support their judgment about the students' retention. Three others described the pressure from school personnel to render specific diagnoses or professional opinions. Finally, a practitioner from the private education sector identified the school's request to use psychological assessment in order to select students as ethically challenging.

\section{Informed Consent and Self-Determination}

Thirty-one (7\%) responses fell into the category named informed consent and self-determination. Nineteen participants described dilemmas about initiating a professional relationship with students without parental consent, namely, when minors self-referred for assistance and wished to maintain secrecy from their legal guardians. Seven participants reported pressure from teachers and administrators to ignore or devalue the need to obtain parental consent prior to psychological evaluation or intervention with students. In this line, three additional incidents were described where the client's right to self-determination and freedom to refuse services were disregarded and the school personnel tried to impose psychological services on students or families. One participant reported doubts about providing psychological assistance to students without parental consent when an immediate intervention was warranted. Another one identified the decision to intervene with students whose parents did not cooperate or involve themselves in the process as an ethical dilemma. They questioned if it was ethically acceptable to discontinue services under these circumstances, acknowledging that without the parents' cooperation most interventions were bound to fail.

\section{Reports and Records}

In the OPP (2011) code, the procedures regarding psychological reports and records are made explicit in the principles of psychological evaluation, privacy and confidentiality. Nevertheless, because participants' answers on this topic frequently allude to both principles, an independent category was created that unifies this subject.

Twenty-seven (6\%) responses fell under this category. Of these, 15 referred to ethical aspects of report writing and the inclusion of clients' information in school documents accessible by other people (e.g., meeting reports, annual service reports, among others). Seven other responses were related with the storage of and access to psychological reports, namely, with their inclusion in students' education records. According to some practitioners, school policies regarding the storage and disposal of students' records did not protect the privacy of psychological information, 
as all school personnel could easily have access to them. Doubts about to whom psychological reports should first be addressed (i.e., parents or teachers) and the need for parental consent to release psychological reports were also described. Four respondents sorted the requests for psychological reports from professionals and agencies outside the school as ethically challenging. One last participant revealed concerns about what kind of client information should be registered.

\section{DISCUSSION}

The purpose of this study was to describe the ethical dilemmas experienced by Portuguese school psychologists, thereby contributing to augment the limited empirical data available on this topic. A sample of 477 school psychologists was surveyed, and almost $60 \%$ of the sample indicated that in the current school year they had faced ethically troubling or challenging situations. The multiplicity of ethical dilemmas described reflects the complexities inherent to psychological practice in schools.

Ethical issues concerning privacy and confidentiality amounted to $53 \%$ of the dilemmas reported, making it the most frequent category. This result is consistent with previous literature which suggests that confidentiality tends to be the most common source of ethical dilemmas for psychologists in diverse specialty areas (Pettifor \& Sawchuk, 2006; Pope \& Vetter, 1992), including school psychology (Dailor \& Jacob, 2011; Jacob-Timm, 1999). In this regard, the practitioners' main difficulties lay in two areas: (a) the disclosure of confidential information to rightful parties or individuals whose collaboration may be essential for an adequate intervention with students, and (b) the decision of whether or not to break confidentiality.

The OPP (2011) code of ethics weaves considerations about privacy and confidentiality when working with minors. It also clarifies the situations where breaching confidentiality and information sharing are ethically appropriate. However, as shown by the results, for psychologists who work with juvenile clients and are employees of the school system these standards can be highly complex (Flanagan \& Miller, 2010). As Jacob et al. (2011) highlighted, because school psychologists work in collaboration with teachers, parents, and others to assist students, it is likely that information will be shared by those involved in the process. The authors also noted that, in this process, tensions between the perceived need of the school to know information about the student and clients' privacy rights are inevitable.

Results clearly suggest that the school personnel and other professionals regularly require or desire to be informed about confidential student/client information. The complexity of the dilemmas surrounding privacy and confidentiality is also magnified due to the parents' right to know information about their children. Nevertheless, school psychologists must be able to explain the limits of confidentiality to all parties at stake, underlining their importance to an effective service delivery. As such, practitioners should invest time and effort to lead others to see them as a trustworthy professional, who know when and what information needs to be discussed, while recognizing the well-being of the client and the client-psychologist relation as priorities. Clarifying the limits of confidentiality can also reinforce the idea that, despite the collaborative nature of psychological intervention, psychologists practice under the ethical principles of professional autonomy and independence.

School psychologists in this study seemed quite vulnerable to difficulties in deciding whether to break confidentiality and how to proceed when facing suspected child abuse and adolescents' 
risky behaviors. These findings are in line with previous research which pointed out that the decision to break confidentiality to protect clients is one of the most frequent dilemmas in professional psychology, including school psychology (Dailor \& Jacob, 2011; Jacob-Timm, 1999; Pettifor, 2004; Pope \& Vetter, 1992; Rae et al., 2009). The Portuguese law establishes that school professionals should report situations of perceived danger to child protective services whenever schools cannot assure the protection needed (Decree-law no. 147/1999). The OPP (2011) code enforces compliance with the law and national guidelines are available to support school interventions (Comissão Nacional de Protecção das Crianças e Jovens em Risco, n.d.). However, it is possible that the dilemmas described may have emerged in more ambiguous scenarios, where the dangerousness of the situation was hard to assess. Another possibility is that some school psychologists lack knowledge, training, and competence regarding child abuse and adolescent risky behaviors to support their professional judgment and ethical decisions. Finally, it is also possible that when faced with children's suffering and vulnerability, professionals become more permeable to their own emotions, which may preclude them from more rational deliberation, as required in ethical decisions.

Despite their relevance, the remaining categories comprised a significantly lower number of dilemmas, in general with more variability. The category Psychological Practice and Intervention ranked second in the total sample, with almost half of the dilemmas within this category referring to conflicts of interest. School psychologists are often school employees and provide services to multiple clients. For this reason, and as shown by the results, conflicting interests are inevitable, leading to the question, Who is the school psychologist's primary client? Is it the student, the student's parents, the teacher, or the school system? (Fisher, 2009; Knauss, 2001). In spite of being a prevailing and highly debatable question within the school psychology field, it was raised by an extremely low number of participants. Such low frequency may reflect that (a) practitioners are aware of their ethical duties towards every party in a case, (b) their concerns focus on other ethical issues more frequently experienced in professional practice, or (c) this issue is so pervasive that practitioners underestimate its significance as an ethical dilemma.

The EFPA Meta-Code of Ethics (2005) defines clients has any direct or indirect recipients of psychological services. In light of this broad definition, even when parents, teachers, or school administrators are defined as primary clients, psychologists still have the ethical obligation to have in mind the child's best interests. Ethical codes, such as the NASP's (2010) and the Canadian Psychological Association's (2000), address these conflicts of interest more straightforwardly by stating that school psychologists act as student advocates or by defining the most vulnerable person as having ethical priorities. The OPP (2011) code is not as explicit in this regard, although it clearly warns psychologists about the effects of their professional actions and the duty to protect clients from harm. The importance of such a statement is reinforced by this study's findings, which suggest that one of the most common dilemmas arising from the relationship with other professionals stems from the observation or knowledge of teachers' unsound educational practices. In North American studies, poor educational practices have been identified among the top three ethical-related concerns for school psychologists (Dailor \& Jacob, 2011; Jacob-Timm, 1999). Although a direct comparison between studies cannot be done due to methodological and cultural differences, this seems to be far less of a concern for Portuguese practitioners.

The second most frequent type of dilemma in the category psychological practice and intervention concerned multiple relationships. The most commonly reported scenarios referred to cases where the school psychologist was asked to establish a professional relationship with someone 
related to the client, or with whom a relationship of a different nature was already existent. Previous literature points out that psychologists in rural areas or small communities are more likely to experience multiple relationships dilemmas, namely, due to the lack of resources available (e.g., Curtin \& Hargrove, 2010; Helbok, Marinelli, \& Walls, 2006; Werth, 2010). Under these circumstances, to guarantee the client's right to access services and prevent potential harm resulting from service denial, multiple relationships such as serving multiple family members may not be avoidable. Although limited in number, this kind of report highlights the need of ethical codes to explicitly acknowledge and adequately address the disparities that may exist between rural and urban settings.

Portuguese school psychologists, like their international counterparts, spend a considerable amount of time in assessment-related activities (Mendes et al., 2014). Thus, it is not surprising that practitioners have expressed concerns on this matter. Although the ethical code contains specific warnings against the use of unreliable, invalid, or outdated tests, this aspect, along with the reproduction of copyrighted test materials, was one of the most cited concerns in the assessment category. Indeed, over the years, the inadequate equipment of school psychology services has recurrently been identified as a barrier to service delivery in Portugal (Centro Interdisciplinar de Estudos Económicos, 2006; Pereira \& Góis, 2000). When working under these conditions, school psychologists may feel tempted to overlook the ethical principles related to psychological testing to fulfill their assessment duties as required by schools. On the other hand, although psychological tests are broadly used in professional practice, assessment techniques whose psychometric qualities are suitable for the Portuguese population are scarce (Almeida \& Peixoto, 2011). These observations lead us to believe that this may be a serious issue for the profession, even if underreported in this study when compared with other previous findings. For example, for North American school psychologists, assessment was found to be among the top three ethicalrelated concerns and the domain where more ethical transgressions were witnessed (Dailor \& Jacob, 2011; Jacob-Timm, 1999). Legal and ethical issues regarding the development and use of tests are generally recognized as a major problem for psychologists around the world and a matter of international concern (Leach \& Oakland, 2007; Oakland et al., 2012).

Informed consent and parental involvement tended to be identified as a major source of ethical dilemmas for school psychologists (Knauss, 2001). Although the data from this study did not confirm this observation, practitioner's answers reflected two specificities of the profession which might leave them particularly exposed to this kind of dilemma: (a) psychological referrals are often made by school personnel, and (b) adolescent students might self-refer for assistance. The OPP (2011) code specifies that, when self-determination is limited due to age, informed consent should be obtained from parents or legal guardians. Nevertheless, it also highlights that psychologists must respect the dignity and autonomy of clients and the collaborative nature of the client-psychologist relationship. From a legal standpoint, at the age of 16, Portuguese citizens are presumed to have the capacity to consent (see article no. 38, Decree-law no. 59/2007). This principle conforms to the legal assumption that, despite the fact that majority starts at age 18, parents must recognize the progressive autonomy of their children (see article no. 123, Decreelaw no. 23/2013). For these reasons, ethical dilemmas related to informed consent may become more complex when working with students around the ages of 16 and up to 18 years. Under these circumstances, but not limited to them, allowing a minor to autonomously refuse or consent to psychological services is a decision that should take into consideration the law, ethical principles, the child's competence to make choices, and the likely consequences of those choices (Jacob 
et al., 2011). Practitioners must also be aware of the limitations of the services delivered without parents' involvement.

A cross-cutting theme to almost all categories concerned pressure to engage in unethical behaviors. Some participants pointed out the pressure to disclose confidential information, place schools' interests ahead of the interests of students, render specific diagnoses, or produce professional opinions and disregard the need to obtain parental consent. Previous research has identified administrative pressure to act unethically as a problem for school psychologists (e.g., Dailor \& Jacob, 2011; Jacob-Timm, 1999; Pope \& Vetter, 1992). However, in this study teachers were also identified as a source of pressure for unethical behavior. The study conducted by Helton et al. (2000) suggested that practitioners who perceived their coworkers as supportive of autonomous decision making were more likely to resist administrative pressure to act unethically. This apparent lack of teachers' awareness or sensitivity to school psychologists' ethical responsibilities may leave Portuguese practitioners more vulnerable to pressures to violate ethical standards. This vulnerability can be also exacerbated if one considers that in schools teachers are in the majority and in most cases the psychologist is the sole representative of their own professional class. Especially when exerted by school administrators, pressure to act unethically can be a very stressful experience (Helton \& Ray, 2006, 2009). The stress and conflicts inherent to these experiences can also be magnified when the hiring and performance appraisal of the school psychologists depends on administrators, as is the case in Portugal. Helton et al. (2000) suggested that practitioners tended to uphold their ethical responsibilities, even when they were pressured to do otherwise, but they also acknowledged that the consequences of resisting such pressures might be dire.

Finally, the high number of participants who reported no ethical dilemmas deserves consideration. This pattern of response has been observed in previous studies, albeit less frequently (Colnerud, 1997; Jacob-Timm, 1999; Pope \& Vetter, 1992; Slack \& Wassenaar, 1999). Different hypotheses have been advanced to explain this pattern of response. On one hand, practitioners may in fact encounter ethical dilemmas but resolve them easily, not feeling the need to report them (Lindsay \& Clarkson, 1999). On the other hand, practitioners may lack knowledge of the ethical and legal aspects of the profession, which results in a lower ability or sensitivity to recognize ethical challenging situations (Jacob et al., 2011), limiting their reports to the situations they are aware of. Other explanations can be related to the desire to promote a positive image of the profession (i.e., of ethical competence) or even attributed to survey design issues that are discussed in the Limitations section.

Several chi-square tests and $t$-tests were conducted to explore differences between participants who did and did not report ethical dilemmas. Only the variable highest level of education attained was able to differentiate the two groups, in which participants with more years of training described ethical dilemmas more frequently. One can hypothesize that school psychologists who completed advanced training programs (e.g., master's or doctoral degree) are more likely to be exposed and called upon to reflect on the ethical aspects of the profession. Therefore, when compared to their colleagues who did not pursue additional training, these practitioners are better prepared to identify ethical dilemmas when they occur. No association was found between the report of ethical dilemmas and years of professional experience. This result suggests that it is not by accumulating years on the job that school psychologists face fewer or more ethical dilemmas, or at least that the recognition of an ethical question does not merely depend on practice length. Previous findings have also highlighted that ethical competence is not merely a function of professional experience (Dailor \& Jacob, 2011). 


\section{Limitations and Future Research}

Despite its practical value, this study has several limitations that deserve consideration. First, due to the sampling and recruitment methods used, the survey sample might not accurately represent the population of school-based psychologists working in public and private schools. Second, the results rely on self-reported and retrospective data, which are prone to numerous sources of bias. Furthermore, the respondents were asked to describe up to three ethical dilemmas encountered during the school year 2011-2012. These restrictions may have hindered capturing the full range of ethical dilemmas experienced by practitioners, although most of them only described one or two incidents. Finally, as previously mentioned, this study was part of a larger survey that addressed several topics of the school psychology profession. Ethical issues were not a central topic of the survey and the questions related to ethics were placed near the end of the survey. It can be hypothesized that the length of the questionnaire and fatigue-related factors may have contributed to the high number of respondents who reported no dilemmas. Nevertheless, it is important to note that the software used to implement the survey allowed participants to save their answers and complete the questionnaire in multiple sessions. The brevity of participants' answers required, in certain cases, subjective analysis by the researchers, who may be criticized for over-interpretation.

As this study was intended to provide an overall picture of the current ethical issues faced by Portuguese school psychologists, many important questions were left unanswered. Future research seeking to extend the current study might benefit from using a structured questionnaire where a list of ethical dilemmas are predetermined based on the findings of previous studies or derived from the OPP (2011) ethical code. It is also important to investigate (a) the frequency of the dilemmas identified in this study, (b) how practitioners manage ethically troubling situations, (c) the primary reasons for their ethical decisions, and (d) what leads practitioners to perceive (or misperceive) a situation as ethically challenging (e.g., lack of experience?, lack of knowledge?, lack of ethical sensitivity?, lack of emotional control?, lack of ethical thinking skills?, lack of courage?). Qualitative methodologies may be especially helpful in accomplishing these last endeavors. Due to the unquestionable importance of ethics education, another area of further research concerns the current state of ethics training in psychology programs. There is a need to understand what ethics courses are teaching and how and if training programs in school and education psychology are addressing the ethical issues unique to the provision of school-based psychological services. Moreover, the survey did not inquire respondents about their professional background in ethics and did not explore the association between ethics training and the reporting of ethical dilemmas. This gap should be overcome in future research. Finally, and because the OPP (2011) code has been available for about 4 years, it would be important to know how often practitioners rely on it to manage ethical dilemmas, how they evaluate its usefulness, and what aspects they perceive as needing to be improved to support school psychology practice.

\section{Practical Implications}

The findings of this study identified three critical issues that need to be addressed to promote the ethical dimension of the practice of school psychology in Portugal: (a) an apparent lack of knowledge by some practicing school psychologists on the ethical aspects of the profession, (b) the need 
for more explicit guidance in specific areas of professional practice in schools, and (c) misinformation or poor understanding from other professionals in the school community about the roles and responsibilities of school psychologists. From this perspective, the implications of this study are vast and may be valuable to current and future practitioners, professional associations, and training institutions.

Overall, results suggest the need to increase the ethical knowledge and skills of school psychologists, namely, those of ethical thinking and decision making, both through initial and long-life education. In Portugal, the focus on ethics training appears to have increased after the restructuring of psychology programs within the framework of the Bologna Process (see Mendes et al., 2014 , for further details). However, as a large body of literature and research recommends, it is important to guarantee that, in the early stages of psychologists' education, all programs offer a formal ethics course that (a) introduces students to ethical and legal standards, (b) heightens self-awareness for personal values and beliefs, and (c) explicitly teaches problem-solving models (e.g., Jacob et al., 2011; Tryon, 2000, 2001; Williams \& Armistead, 2011). In more advanced stages, training programs should ensure that ethical issues related to areas of specialty are discussed, namely, by integrating ethics across the curriculum of multiple classes and in supervised practicum and internship experiences (Tryon, 2000). As previously mentioned, although the OPP (2011) code states that ethical thinking and conduct should be taught and promoted at all education levels, at national level this is far from happening.

Continuing education activities and supervision are recognized as crucial vehicles by which school psychologists can update and develop new knowledge and skills (Williams \& Armistead, 2011). Even though foundational courses on ethics, conferences, seminars, and books (e.g., Ricou, 2004, 2014) are becoming available to Portuguese practitioners, few school psychologists actually receive supervision. Although after several years of practice most school psychologists operate at a competent level, it is acknowledged that effective supervision is required to move beyond that (Harvey \& Struzziero, 2008). To this end, it is fundamental to advance a sustainable model for the supervision of the practitioners in the field that focuses the discussion on the ethical aspects of the profession. School psychologists must understand professional ethics as a requirement that permeates all areas of practice, as well as a condition that enhances the quality of services provided and protects the rights of all parties (NASP, 2006; Williams \& Armistead, 2011).

Increased efforts by professional organizations to promote school psychologists' awareness, knowledge, and skills of professional ethics are also needed. Although the OPP is now providing access to e- and b-learning courses in ethics, it is important to expand the resources and variety of learning and professional development opportunities offered to its members. An example would be to invest in the development of freely available self-study materials on key ethical concepts (e.g., articles, case studies, videos, and podcasts), encouraging practitioners to take responsibility for their own continuous education. Creating face-to-face and Internet forums, focused on ethical issues, would be another way to provide school psychologists with access to formal peer support groups and/or mentoring networks. An alternative would be for the OPP to offer formal consultation services to practitioners in this regard. In the medium to short term, the OPP foresees the creation of an ethics committee, which will have responsibilities in the development of guidelines and position papers, to promote the ethical practice of psychology. This entity could also play a major role in the provision of ethical consultations to psychologists. 
Of no less importance is to advance with nationally approved guidelines for psychological practice in schools to promote consistent ethical choices, behaviors, and procedures. The OPP is on the verge of publishing guidelines for interprofessional communication and sharing of information, which have implications for school psychologists and will certainly help to clarify this subject. Nevertheless, the results of this study also suggest that school psychologists would benefit from more detailed guidance regarding (a) reporting child abuse and family violence, (b) responding to pressure to act unethically, (c) and report writing.

Last, actively informing key stakeholders about the roles and responsibilities of school psychologists may increase the public knowledge and understanding of the boundaries and ethical commitments of the profession. We hope that this strategy could help to decrease, among others, ethical dilemmas related to conflicts of interests, dual relationships, competence, and pressure for unethical practice. School psychologists must recognize their own ethical responsibility to advance with such pedagogical initiatives within their school setting. However, one must admit that practitioners may not be prepared to carry out this task, needing first and foremost to improve their own ethical and communication skills.

\section{Final Considerations}

The results of this study illustrate the broad and complex range of ethical dilemmas faced by Portuguese school psychologists. They clearly show that the mere existence of an ethical code does not guarantee practitioners' ethical knowledge and thinking. At a national level, it is expected that this study serves as an impetus for the discussion of school psychologists' ethical conduct and professional practices, to promote ethics training and education, and support the development of professional guidelines. Furthermore, this study is expected to encourage future research that will allow building a cross-cultural perspective on the ethical issues affecting school psychology.

\section{ACKNOWLEDGMENTS}

We thank all school psychologists who participated in this study, the Directorate-General of Education for supporting data collection, and Silvia Marques for the support in the data analysis.

\section{FUNDING}

This research was financially sponsored by the Portuguese Foundation for Science and Technology (Doctoral grant, SFRH/BD/78646/2011).

\section{REFERENCES}

Almeida, L. S., \& Peixoto, F. (2011). A psicologia da educação [The psychology of education]. In M. P. Lopes, P. J. Palma, R. Bártolo-Ribeiro, \& M.P. Cunha, (Eds.), Manual de Psicologia Aplicada (pp. 47-68). Lisboa, Portugal: RH Editora.

American Psychological Association. (2010). Ethical principles of psychologists and code of conduct. Retrieved from http://www.apa.org/ethics/code/ 
Canadian Psychological Association. (2000). Canadian code of ethics for psychologists. Retrieved from http://www.cpa. ca/aboutcpa/committees/ethics/codeofethics

Carita, A. (2012). Psicologia e psicólogos escolares: Perfil e confrontos éticos [Psychology and school psychologists: Profile and ethical confrontations]. Lisboa, Portugal: Edições Universitárias Lusófonas.

Centro Interdisciplinar de Estudos Económicos. (2006). Estudo sobre a intervenção no contexto escolar dos serviços de psicologia e orientação [Study about intervention in school context of psychology and guidance services]. Lisboa, Portugal: Direção Geral de Inovação e Desenvolvimento Curricular.

Clemente, M., Espinosa, P., \& Urra, J. (2011). Ethical issues in psychologists' professional practice: Agreement over problematic professional behaviors among Spanish psychologists. Ethics \& Behavior, 21, 13-34. doi:10.1080/10508422.2011.537568

Colnerud, G. (1997). Ethical dilemmas of psychologists: A Swedish example in an international perspective. European Psychologist, 2, 164-170. doi:10.1027/1016-9040.2.2.164

Comissão Nacional de Protecção das Crianças e Jovens em Risco. (n.d.). Guia de orientações para os profissionas da educação na abordagem de situações de maus tratos ou outras situações de risco [Guidelines for professionals in education to the approach to mistreatment or other risk conditions]. Retrieved from http://www.cnpcjr.pt/guias/ Guia_Educacao.pdf

Curtin, L., \& Hargrove, D. S. (2010). Opportunities and challenges of rural practice: Managing self amid ambiguity. Journal of Clinical Psychology, 66, 549-561. doi:10.1002/jclp.20687

Dailor, A. N., \& Jacob, S. (2011). Ethically challenging situations reported by school psychologists: Implications for training. Psychology in the Schools, 48, 619-631. doi:10.1002/pits.20574

Decree-law no. 190/1991 of 17th May 1991. Decrees the creation, nature, and attributions of psychology and guidance services.

Decree-law no. 147/1999 of 1st September 1999. Law of protection of children and youth at risk.

Decree-law no. 59/2007 of 4th September. Twenty-third amendment to the criminal code.

Decree-law no. 3/2008 of 7th January 2008. Defines the support to be provided to students with special education needs.

Decree-law no. 57/2008 of 4th September 2008. Creates the Portuguese Order of Psychologists and approves its statute.

Decree-law no. 51/2012 of 5th September 2012. Approves the statute of student and school ethics.

Decree-law no. 23/2013 of 5th March. Sixty-second amendment to the civil code.

European Commission. (2013). The Bologna process: Towards the European higher education area. Retrieved from http://ec.europa.eu/education/policy/higher-education/bologna-process_en.htm

European Federation of Psychologists' Associations. (2005). Meta-code of ethics. Retrieved from http://www.efpa.eu/ ethics

European Federation of Psychologists' Associations. (2013). EuroPsy - The European certificate in psychology. Retrieved from http://www.europsy-efpa.eu/regulations

Fagan, T. K., \& Wise, P. S. (2007). School psychology: Past, present and future (3rd ed.). Bethesda, MD: National Association of School Psychologists.

Fisher, M. A. (2009). Replacing "who is the client?" with a different ethical question. Professional Psychology: Research and Practice, 40, 1-7. doi:10.1037/a0014011

Flanagan, R., \& Miller, J. A. (2010). Specialty competencies on school psychology. New York, NY: Oxford University Press.

Gauthier, J., Pettifor, J., \& Ferrero, A. (2010). The universal declaration of ethical principles for psychologists: A culture-sensitive model for creating and reviewing a code of ethics. Ethics \& Behavior, 20, 179-196. doi:10.1080/10508421003798885

Gutkin, T. B., \& Conoley, J. C. (1990). Reconceptualizing school psychology from a service delivery perspective: Implications for practice, training, and research. Journal of School Psychology, 28, $203-223$. doi:10.1016/0022-4405(90)90012-V

Harvey, V. S., \& Struzziero, J. A. (2008). Professional development and supervision of school psychologists: From intern to expert (2nd ed.). Thousand Oaks, CA: Corwin Press.

Helbok, C. M., Marinelli, R. P., \& Walls, R. T. (2006). National survey of ethical practices across rural and urban communities. Professional Psychology: Research and Practice, 37, 36-44. doi:10.1037/0735-7028.37.1.36

Helton, G. B., \& Ray, B. A. (2006). Strategies school practitioners report they would use to resist pressures to practice unethically. Journal of Applied School Psychology, 22, 43-65. doi:10.1300/J370v22n01_03 
Helton, G. B., \& Ray, B. A. (2009). Administrative pressures to practice unethically: Research and suggested strategies. Ethical Human Psychology and Psychiatry, 11, 112-119. doi:10.1891/1559-4343.11.2.112

Helton, G. B., Ray, B. A., \& Biderman, M. D. (2000). Responses of school psychologists and special education teachers to administrative pressures to practice unethically. Special Services in the Schools, 16, 111-134. doi:10.1300/J008v16n01_08

International School Psychology Association. (2011). Code of ethics. Retrieved from http://www.ispaweb.org/wp-content/ uploads/2013/01/The_ISPA_Code_of_Ethics_2011.pdf

Jacob, S., Decker, D., \& Hartshorne, T. (2011). Ethics and law for school psychologists (6th ed.). Hoboken, NJ: Wiley.

Jacob-Timm, S. (1999). Ethically challenging situations encountered by school psychologists. Psychology in the Schools, 36, 205-217. doi:10.1002/(ISSN)1520-6807

Knauss, L. K. (2001). Ethical issues in psychological assessment in school settings. Journal of Personality Assessment, 77, 231-241. doi:10.1207/S15327752JPA7702_06

Koocher, G. P. (2008). Ethical challenges in mental health services to children and families. Journal of Clinical Psychology, 64, 601-612. doi:10.1002/jclp.20476

Lasser, J., \& Klose, L. M. (2007). School psychologists' ethical decision making: Implications from selected social psychological phenomena. School Psychology Review, 36, 484-500.

Leach, M. M., \& Oakland, T. (2007). Ethics standards impacting test development and use: A review of 31 ethics codes impacting practices in 35 countries. International Journal of Testing, 7, 71-88. doi:10.1080/15305050709336859

Lindsay, G., \& Clarkson, P. (1999). Ethical dilemmas of psychotherapists. The Psychologist, 14, 182-185.

Lindsay, G., \& Coloney, A. (1995). Ethical dilemmas of members of the society. The Psychologist, 8, 448-451.

McNamara, K. M. (2011). Ethical considerations in the practice of school psychology. In M. Bray \& T. J. Kehle (Eds.), The Oxford handbook of school psychology (pp. 762-773). New York, NY: Oxford University Press.

Mendes, S. A., Abreu-Lima, I., Almeida, L. S., \& Simeonsson, R. J. (2014). School psychology in Portugal: Practitioners' characteristics and practices. International Journal of School \& Educational Psychology, 2, 115-125. doi:10.1080/21683603.2013.863171

Menezes, I., Teixeira, P. M., \& Fidalgo, M. (2007). Community psychology in Portugal: From revolution to empowered citizenship. In S. Reich, M. Riemer, I. Prilleltensky, \& M. Montero (Eds.), International community psychology: History and theories (pp. 317-334). New York, NY: Springer.

National Association of School Psychologists. (2006). School psychology: A blueprint for training in practice III. Bethesda, MD: Author.

National Association of School Psychologists. (2010, January). Principles of professional ethics. Retrieved from http:// www.nasponline.org/standards/ethics/index.aspx

Normative order no. 13/2014 of 15th September 2012. Regulates the assessment and certification of student's achievements and skills at basic education level.

Oakland, T., Leach, M. M., Bartram, D., Lindsay, G., Smedler, A.-C., \& Zhang, H. (2012). An international perspective on ethics codes for psychology: A focus on test development and use. In A. Ferrero, Y. Korkut, M. M. Leach, G. Lindsay, \& M. J. Stevens (Eds.), Handbook of international psychological ethics (pp. 19-27). New York, NY: Oxford University Press.

Order of Portuguese Psychologists. (2011). Code of ethics. Retrieved from https://www.ordemdospsicologos.pt/ficheiros/ documentos/opp_cod_deontologico_web.pdf

Order of Portuguese Psychologists. (2012). Retrato de uma profissão: Quem somos, quantos somos? [Portrait of a profession: Who we are, how many we are?]. Psis, 21, 21-23.

Order of Portuguese Psychologists. (2014). Os números da ordem: Resultados do censo dos membros efetivos [The numbers of the order: Results from the census to the effective members]. Lisbon, Portugal: Author.

Ordinance no. 292-A/2012 of 26th September 2012. Launches a pilot experiment to offer vocational courses in elementary education.

Pereira, F., \& Góis, C. (2000). Observatório dos serviços de psicologia e orientação [Observatory of psychology and guidance services]. Lisbon, Portugal: Ministério da Educação - Departamento da Educação Básica Núcleo de Orientação Educativa e de Educação Especial.

Pettifor, J. L. (2004). Professional ethics across national boundaries. European Psychologist, 9, $264-272$. doi:10.1027/1016-9040.9.4.264

Pettifor, J. L., \& Sawchuk, T. R. (2006). Psychologists' perceptions of ethically troubling incidents across international borders. International Journal of Psychology, 41, 216-225. doi:10.1080/00207590500343505 
Pope, K. S., \& Vetter, V. A. (1992). Ethical dilemmas encountered by members of the American Psychological Association: A national survey. The American Psychologist, 47, 397-411. doi:10.1037/0003-066X.47.3.397

Rae, W. A., Sullivan, J. R., Razo, N. P., \& Alba, R. G. (2009). Breaking confidentiality to report adolescent risk-taking behavior by school psychologists. Ethics \& Behavior, 19, 449-460. doi:10.1080/10508420903274930

Ricou, M. (2004). Ética e psicologia: Uma prática integrada [Ethics and psychology: An Integrated Practice]. Coimbra, Portugal: Gráfica de Coimbra.

Ricou, M. (2014). A ética e a deontologia no exercício da psicologia [The ethics and deontology in the practice of psychology]. Lisbon, Portugal: Order of Portuguese Psychologists.

Sinclair, C., Poizner, S., Gilmour-Barrett, K., \& Randall, D. (1987). The development of a code of ethics for Canadian psychologists. Canadian Psychology/ Psychologie Canadienne, 28, 1-8. doi:10.1037/h0079883

Slack, C. M., \& Wassenaar, D. R. (1999). Ethical dilemmas of South African clinical psychologists. European Psychologist, 4, 179-186. doi:10.1027/1016-9040.4.3.179

Tryon, G. S. (2000). Ethical transgressions of school psychology graduate students: A critical incidents survey. Ethics \& Behavior, 10, 271-279. doi:10.1207/S15327019EB1003_5

Tryon, G. S. (2001). School psychology students' beliefs about their preparation and concern with ethical issues. Ethics \& Behavior, 11, 375-394. doi:10.1207/S15327019EB1104_02

Werth, J. (2010). Ethical challenges of practicing in rural areas. Journal of Clinical Psychology, 66, 537-548. doi: $10.1002 /$ jclp. 20681

Williams, B. B., \& Armistead, L. (2011). Applying law and ethics in professional practice. In T. M. Lionetti, E. P. Snyder, $\&$ R. W. Christner (Eds.), A practical guide to building professional competencies in school psychology (pp. 13-34). New York, NY: Springer. 